\title{
Noise and Light Pollution in the Hospital: A Call for Action
}

\author{
Biren B. Kamdar, MD, MBA, MHS ${ }^{1 *}$, Jennifer L. Martin, PhD ${ }^{2,3}$, Dale M. Needham, FCPA, MD, PhD ${ }^{4,5,6}$
}

\begin{abstract}
${ }^{1}$ Division of Pulmonary and Critical Care Medicine, David Geffen School of Medicine at the University of California at Los Angeles, Los Angeles, California; '2Department of Medicine, David Geffen School of Medicine at the University of California at Los Angeles, Los Angeles, California; ${ }^{3}$ Veterans Affairs Greater Los Angeles Healthcare System, Geriatric Research Education and Clinical Center, Los Angeles, California; ${ }^{4}$ Outcomes After Critical Illness and Surgery Group, Johns Hopkins University, Baltimore, Maryland; '5ivision of Pulmonary and Critical Care Medicine, Johns Hopkins University, Baltimore, Maryland; ${ }^{6}$ Department of Physical Medicine and Rehabilitation, Johns Hopkins University, Baltimore, Maryland.
\end{abstract}

"Unnecessary noise is the most cruel abuse of care which can be inflicted on either the sick or the well." -Florence Nightingale ${ }^{1}$

Motivated by the "unsustainable" rise in noise pollution and its "direct, as well as cumulative, adverse health effects," an expert World Health Organization (WHO) task force composed the Guidelines for Community Noise, outlining specific noise recommendations for public settings, including hospitals. ${ }^{2}$ In ward settings, these guidelines mandate that background noise (which is defined as unwanted sound) levels average $<35$ decibels ( $\mathrm{dB}$; ie, a typical library) during the day, average $<30 \mathrm{~dB}$ at night, and peak no higher than 40 $\mathrm{dB}$ (ie, a normal conversation), a level sufficient to awaken someone from sleep.

Since the publication of these guidelines in 1999, substantial new research has added to our understanding of hospital noise levels. Recent research has demonstrated that few, if any, hospitals comply with WHO noise recommendations. ${ }^{3}$ Moreover, since 1960, hospital sound levels have risen $\sim 4$ $\mathrm{dB}$ per decade; based on the logarithmic decibel scale, if this trend continues, this translates to a $528 \%$ increase in loudness by $2020 .^{3}$

The overwhelming majority of research on hospital noise has focused on the intensive care unit (ICU), where beeping machines and busy staff often push peak nighttime noise levels over $80 \mathrm{~dB}$ (ie, a kitchen blender). ${ }^{4}$ When evaluated during sleep, noise in the ICU causes frequent arousals and awakenings. When noise is combined with other factors, such as bright light and patient care interactions, poor sleep quality invariably results. ${ }^{4}$

While it has been known for years that critically ill patients experience markedly fragmented and nonrestorative sleep, ${ }^{5}$ poor sleep has recently gained attention due to its potential role as a modifiable risk factor for delirium and its associated consequences, including prolonged length of stay

\footnotetext{
*Address for correspondence and reprint requests: Biren B. Kamdar, MD, MBA, MHS, Division of Pulmonary and Critical Care Medicine, David Geffen School of Medicine at UCLA, 10833 Le Conte Ave., Room 37-131 CHS, Los Angeles, CA 90095; Telephone: 310-825-3763; Fax: 310-206-8622;

E-mail: bkamdar@mednet.ucla.edu
}

Received: July 5, 2017; Accepted: July 11, 2017

2017 Society of Hospital Medicine DOI 10.12788/jhm.2838 and long-lasting neuropsychological and physical impairments. ${ }^{6}$ Due to this interest, numerous interventions have been attempted, ${ }^{7}$ including multicomponent bundles to promote sleep, ${ }^{8}$ which have been shown to reduce delirium in the ICU. ${ }^{9-12}$ Therefore, efforts to promote sleep in the ICU, including interventions to minimize nighttime noise, are recommended in Society of Critical Care Medicine clinical practice guidelines ${ }^{13}$ and are listed as a top 5 research priority by an expert panel of ICU delirium researchers. ${ }^{14}$

In contrast to the ICU, there has been little attention paid to noise in other patient care areas. Existing studies in nonICU ward settings suggest that excessive noise is common, ${ }^{3}$ similar to the ICU, and that patients experience poor sleep, with noise being a significant disruptor of sleep. ${ }^{5,15,16}$ Such poor sleep is thought to contribute to uncontrolled pain, labile blood pressure, and dissatisfaction with care. ${ }^{16,17}$

In this issue of the Journal of Hospital Medicine, Jaiswal and colleagues ${ }^{18}$ report on an important study evaluating sound and light levels in both non-ICU and ICU settings within a busy tertiary-care hospital. In 8 general ward, 8 telemetry, and $8 \mathrm{ICU}$ patient rooms, the investigators used meters to record sound and light levels for 24 to 72 hours. In each of these locations, they detected average hourly sound levels ranging from 45 to $54 \mathrm{~dB}, 47$ to $55 \mathrm{~dB}$, and 56 to $60 \mathrm{~dB}$, respectively, with ICUs consistently registering the highest hourly sound levels. Notably, all locations exceeded WHO noise limits at all hours of the day. As a novel measure, the investigators evaluated sound level changes (SLCs), or the difference between peak and background sound levels, based on research suggesting that dramatic SLCs $(\geq 17.5 \mathrm{~dB})$ are more disruptive than constant loud noise. ${ }^{19}$ The authors observed that SLCs $\geq 17.5 \mathrm{~dB}$ occur predominantly during daytime hours and, interestingly, at a similar rate in the wards versus the ICU.

Importantly, the authors do not link their findings with patient sleep or other patient outcomes but instead focus on employing rigorous methods to gather continuous recordings. By measuring light levels, the authors bring attention to an issue often considered less disruptive to sleep than noise. ${ }^{6,10,20}$ Similar to prior research, ${ }^{21}$ Jaiswal and colleagues demonstrate low levels of light at night, with no substantial difference between non-ICU and ICU settings. As a key finding, the authors bring attention to low levels of light during daytime hours, particularly in the morning, when levels range from 22 to 101 lux in the wards and 16 to 39 
lux in the ICU. While the optimal timing and brightness of light exposure remains unknown, it is well established that ambient light is the most potent cue for circadian rhythms, with levels $>100$ lux necessary to suppress melatonin, the key hormone involved in circadian entrainment. Hence, the levels of morning light observed in this study were likely insufficient to maintain healthy circadian rhythms. When exposed to abnormal light levels and factors such as noise, stress, and medications, hospitalized patients are at risk for circadian rhythm misalignment, which can disrupt sleep and trigger a complex molecular cascade, leading to end-organ dysfunction including depressed immunity, glucose dysregulation, arrhythmias, and delirium. ${ }^{22-24}$

What are the major takeaway messages from this study? First, it confirms that sound levels are not only high in the ICU but also in non-ICU wards. As hospital ratings and reimbursements now rely on favorable patient ratings, future noise-reduction efforts will surely expand more vigorously across patient care areas..$^{25}$ Second, SLCs and daytime recordings must be included in efforts to understand and improve

\section{References}

1. Nightingale F. Notes on Nursing: What It Is, and What It Is Not. Harrison; 1860.

2. Berglund B, Lindvall T, Schwela DH. Guidelines for Community Noise. Geneva, Switzerland: World Health Organization, 1999. http://www.who.int/docstore/peh/ noise/guidelines2.html. Accessed on June 23, 2017.

3. Busch-Vishniac IJ, West JE, Barnhill C, Hunter T, Orellana D, Chivukula R. Noise levels in Johns Hopkins Hospital. J Acoust Soc Am. 2005;118(6):3629-3645.

4. Kamdar BB, Needham DM, Collop NA. Sleep deprivation in critical illness: its role in physical and psychological recovery. J Intensive Care Med. 2012;27(2): 97-111.

5. Knauert MP, Malik V, Kamdar BB. Sleep and sleep disordered breathing in hospitalized patients. Semin Respir Crit Care Med. 2014;35(5):582-592.

6. Kamdar BB, Knauert MP, Jones SF, et al. Perceptions and practices regarding sleep in the intensive care unit. A survey of 1,223 critical care providers. Ann Am Thorac Soc. 2016;13(8):1370-1377.

7. DuBose JR, Hadi K. Improving inpatient environments to support patient sleep. Int J Qual Health Care. 2016;28(5):540-553.

8. Kamdar BB, Kamdar BB, Needham DM. Bundling sleep promotion with delirium prevention: ready for prime time? Anaesthesia. 2014;69(6):527-531.

9. Patel J, Baldwin J, Bunting P, Laha S. The effect of a multicomponent multidis ciplinary bundle of interventions on sleep and delirium in medical and surgical intensive care patients. Anaesthesia. 2014;69(6):540-549.

10. Kamdar BB, King LM, Collop NA, et al. The effect of a quality improvement intervention on perceived sleep quality and cognition in a medical ICU. Crit Care Med. 2013;41(3):800-809.

11. van de Pol I, van Iterson M, Maaskant J. Effect of nocturnal sound reduction on the incidence of delirium in intensive care unit patients: An interrupted time series analysis. Intensive Crit Care Nurs. 2017;41:18-25.

12. Flannery AH, Oyler DR, Weinhouse GL. The impact of interventions to improve sleep on delirium in the ICU: a systematic review and research framework. Crit Care Med. 2016;44(12):2231-2240.

13. Barr J, Fraser GL, Puntillo K, et al. Clinical practice guidelines for the management of pain, agitation, and delirium in adult patients in the intensive care unit. Crit Care Med. 2013;41(1):263-306.

14. Pandharipande PP, Ely EW, Arora RC, et al. The intensive care delirium research sleep and circadian rhythms in hospitalized patients. Finally, this study provides a sobering reminder of the challenge of meeting WHO guidelines and facilitating an optimal healing environment for patients. Sadly, hospital sound levels continue to rise, and quiet-time interventions consistently fail to lower noise to levels anywhere near WHO limits. ${ }^{26}$ Hence, to make any progress, hospitals of the future must entertain novel design modifications (eg, sound-absorbing walls and alternative room layouts), fix common sources of noise pollution (eg, ventilation systems and alarms), and critically evaluate and update interventions aimed at improving sleep and aligning circadian rhythms for hospitalized patients. ${ }^{27}$

\section{Acknowledgments}

B.B.K. is currently supported by a grant through the University of California, Los Angeles Clinical Translational Research Institute and the National Institutes of Health's National Center for Advancing Translational Sciences (UL1TR000124).

Disclosure: The authors have nothing to disclose.

agenda: a multinational, interprofessional perspective [published online ahead of print June 13, 2017]. Intensive Care Med.

15. Topf M, Thompson S. Interactive relationships between hospital patients' noise-induced stress and other stress with sleep. Heart Lung. 2001;30(4):237-243.

16. Tamrat R, Huynh-Le MP, Goyal M. Non-pharmacologic interventions to improve the sleep of hospitalized patients: a systematic review. J Gen Intern Med. 2014;29(5):788-795.

17. Fillary J, Chaplin H, Jones G, Thompson A, Holme A, Wilson P. Noise at night in hospital general wards: a mapping of the literature. Br J Nurs. 2015;24(10):536-540.

18. Jaiswal SJ, Garcia S, Owens RL. Sound and light levels are similarly disruptive in ICU and non-ICU wards. J Hosp Med. 2017;12(10):798-804. https://doi. org/10.12788/jhm.2826.

19. Stanchina ML, Abu-Hijleh M, Chaudhry BK, Carlisle CC, Millman RP. The influence of white noise on sleep in subjects exposed to ICU noise. Sleep Med. 2005;6(5):423-428.

20. Freedman NS, Kotzer N, Schwab RJ. Patient perception of sleep quality and etiology of sleep disruption in the intensive care unit. Am J Respir Crit Care Med. 1999;159(4, Pt 1):1155-1162.

21. Meyer TJ, Eveloff SE, Bauer MS, Schwartz WA, Hill NS, Millman RP. Adverse environmental conditions in the respiratory and medical ICU settings. Chest. 1994;105(4):1211-1216.

22. Castro R, Angus DC, Rosengart MR. The effect of light on critical illness. Crit Care. 2011;15(2):218.

23. Brainard J, Gobel M, Scott B, Koeppen M, Eckle T. Health implications of disrupted circadian rhythms and the potential for daylight as therapy. Anesthesiology. 2015;122(5):1170-1175.

24. Fitzgerald JM, Adamis D, Trzepacz PT, et al. Delirium: a disturbance of circadian integrity? Med Hypotheses. 2013;81(4):568-576.

25. Stafford A, Haverland A, Bridges E. Noise in the ICU. Am J Nurs. 2014;114(5): 57-63.

26. Tainter CR, Levine AR, Quraishi SA, et al. Noise levels in surgical ICUs are consistently above recommended standards. Crit Care Med. 2016;44(1):147-152.

27. Ulrich RS, Zimring $\mathrm{C}$, Zhu X, et al. A review of the research literature on evidence-based healthcare design. HERD. 2008;1(3):61-125. 